\title{
Hydrogen Gas Improves Seed Germination in Cucumber by Regulating Sugar and Starch Metabolisms
}

\author{
Panpan Huang, Changxia Li, Huwei Liu, Zongxi Zhao and Weibiao Liao *(D) \\ College of Horticulture, Gansu Agricultural University, 1 Yinmen Village, Anning District, \\ Lanzhou 730070, China; huangpp2243739575@163.com (P.H.); licxgsau5@163.com (C.L.); \\ lhwgsauedu@163.com (H.L.); zhaozongxi2021@163.com (Z.Z.) \\ * Correspondence: liaowb@gsau.edu.cn; Tel.: +86-931-7632155
}

Citation: Huang, P.; Li, C.; Liu, H.; Zhao, Z.; Liao, W. Hydrogen Gas Improves Seed Germination in Cucumber by Regulating Sugar and Starch Metabolisms. Horticulturae 2021, 7, 456. https://doi.org/ 10.3390/horticulturae7110456

Academic Editor: Hongmei Du

Received: 17 October 2021

Accepted: 24 October 2021

Published: 3 November 2021

Publisher's Note: MDPI stays neutral with regard to jurisdictional claims in published maps and institutional affiliations.

Copyright: (C) 2021 by the authors. Licensee MDPI, Basel, Switzerland. This article is an open access article distributed under the terms and conditions of the Creative Commons Attribution (CC BY) license (https:/ / creativecommons.org/licenses/by/ $4.0 /)$.

\begin{abstract}
Hydrogen gas $\left(\mathrm{H}_{2}\right)$, an important gaseous regulator, is involved in various plant growth and development processes. However, there have been few studies on the role of $\mathrm{H}_{2}$ in seed germination. In this study, the role and underlying mechanisms of $\mathrm{H}_{2}$ in enhancing seed germination were investigated in cucumber (Cucumis sativus L.). The results revealed that the germination rate, germ length, germination index, and vitality index of cucumber exhibited a dose-dependent relationship with the increase in concentrations of hydrogen-rich water (HRW, a $\mathrm{H}_{2}$ donor; $0,1,10,25,50,75$, and $100 \%$ ), attaining the maximum values with 75\% HRW treatment. Treatment with $75 \%$ HRW resulted in higher contents of soluble sugar, soluble protein, and starch than the control. Additionally, the activity of $\alpha$-amylase, $\beta$-amylase, and total amylase was significantly improved by $75 \% \mathrm{HRW}$ treatment compared to the control, reaching the maximum values at $36 \mathrm{~h}$. Moreover, the expression levels of starch-related genes $A M Y$ and $B M Y$ and sugar-related genes SS4 and SS3 were significantly upregulated by $75 \%$ HRW treatment during germination, particularly at $36 \mathrm{~h}$. These results suggest that $\mathrm{H}_{2}$ might promote cucumber seed germination by increasing sugar and starch metabolisms.
\end{abstract}

Keywords: hydrogen-rich water (HRW); carbohydrate; $\alpha$-amylase; $\beta$-amylase; gene expression; seed germination; Cucumis sativus L.

\section{Introduction}

Some small gas molecules, including hydrogen sulfide $\left(\mathrm{H}_{2} \mathrm{~S}\right)$, nitric oxide (NO), and carbon monoxide (CO), are involved in a range of physiological and developmental procedures in plants, such as adventitious rooting, horticultural production freshness, stomatal movement, and endogenous ethylene biosynthesis. Recently, $\mathrm{H}_{2}$ has been found to be a novel antioxidant in animals and plants. $\mathrm{H}_{2}$ can respond to physiological processes as a novel beneficial gaseous molecule [1-3]. $\mathrm{H}_{2}$ has been reported to be involved in a series of events in plant growth and development [4,5]. Moreover, a previous study showed that $\mathrm{H}_{2}$ could regulate stomata closure and anthocyanin synthesis under UV-A irradiation stress [6]. Additionally, $\mathrm{H}_{2}$ responds to some abiotic stresses, including salinity [7], heavy metals [8], osmotic stress [9], high light stress [10], and temperature stress [11]. For instance, hydrogen-rich water ( $\mathrm{HRW}, \mathrm{a} \mathrm{H}_{2}$ donor) enhanced the salt tolerance of Arabidopsis by increasing antioxidant system, counteracting ROS overproduction and lipid peroxidation [7]. Furthermore, the application of HRW can delay postharvest senescence and improve the quality of cut flowers [12-15]. For example, HRW prolonged the vase life of cut rose flowers by maintaining proper water balance and membrane stability and alleviating oxidative damage [12]. The vase life of cut lisianthus flowers was delayed by endogenous $\mathrm{H}_{2}$ by maintaining redox homeostasis [13]. The application of HRW delayed postharvest senescence and improved the quality of cut rose flowers by repressing endogenous ethylene production and alleviating ethylene signal transduction [14]. HRW improved the vase life and ornamental quality of cut rose flowers by decreasing the clogging of bacteria in the blood vessels of the xylem and increasing the abundance of beneficial bacteria [15]. 
Seed germination is crucial for the growth and yield of crop plants. Typically, seed germination starts from the imbibition of dried and mature seeds and ends with the protruding radicle [16]. The proper environmental condition is important for seed germination, including light [17], temperature [18], nutrient, and soil water content [19]. Phytohormones are also related to seed germination, including abscisic acid (ABA), gibberellins (GAs), and ethylene [20,21]. Moreover, ethylene plays a significant role in regulating seed germination as a natural plant hormone produced at later stages of seed germination [22]. Small molecular gases are also involved in the seed germination process. For example, hydrogen sulfide $\left(\mathrm{H}_{2} \mathrm{~S}\right)$ alleviated nitrate stress and promoted tomato seed germination [23]. The application of nitric oxide (NO) alleviated the inhibitory effect of ABA on seed germination and early growth of seedlings by breaking seed dormancy [24]. Additionally, under salt stress, $\mathrm{H}_{2}$ independently accelerated the seed germination of rice by increasing energy resources. During seed development, once enough water is absorbed, different kinds of metabolites are activated, including soluble sugar, protein, and starch. Soluble sugars are simple carbohydrates composed primarily of carbon, hydrogen, and oxygen. They play a central role in metabolism as sources of energy and as building blocks for synthesis of structural and nonstructural polymers [25]. Soluble proteins are important as osmotic adjustment substances and nutrients. The accumulation of soluble proteins can improve the water retention capacity of cells and protect vital substances [26]. A large amount of starch was found in the endosperm during rice seed germination [27]. It has been reported that HRW facilitates the conversion of starch into sugars [28]. The $\alpha$-amylase has been proven to attach to starch granule and help release the soluble glucans, which might contribute to elevated germination percentage. In addition, a previous study showed that the content of total water-soluble carbohydrate, proline, and soluble protein was enhanced by hemin and CO in Cassia obtusifolia L. [29].

Seed germination is a hyperaction phase that requires tremendous energy. Starch, which provides the needed energy and material for seed germination and seedling development, is one of the main stored substances in seed. The activities of relevant enzymes ( $\alpha$ - and $\beta$-amylase) were upregulated by melatonin, thereby promoting starch catabolism for adenosine triphosphate (ATP) production [7]. Starch metabolism is regulated by a series of genes and enzymes. The alpha amylase (AMY) and beta amylase (BMY) are the key enzymes in the starch hydrolytic process [26]. In rice, $\alpha / \beta$-amylase activities were activated by HRW treatment [28,30]. Thus, the total soluble sugar is formed rapidly. Large amounts of nutrients, including soluble sugar, proteins, and starch, are all accumulated with the germination of seed. The cellular structure and enzyme activities are gradually resumed during this process. Major metabolism-related enzymes are accumulated and kept stable to increase the germination rate of mature dry seeds [28,31]. Similarly, soluble proteins are composited during the late period of seed germination and deposited in protein storage vacuoles in mature seeds [19]. These proteins, which are activated during seed germination, could provide nutrients for seedling growth [26]. It has been reported that melatonin might regulate storage protein catabolism under salt stress [7]. Starch hydrolysis and sucrose transport play an important role in seed germination and seedling growth. In wheat, sucrose is considered to be the major sugar present in the endosperm in the early stage of germination, whereas maltose and glucose are predominant at a later stage [32]. The physiological role of sucrose synthesis (SS) is generally considered to affect sucrose degradation [33]. The hydrolysis of translocated carbohydrate is considered an integral part of sugar accumulation in Zea mays [10] and Saccharum sp. [34]. In cucumber, extensive metabolisms of stachyose occur in fruit peduncles [35]. In Arabidopsis seeds, sugar is one of the major nutrients stored in cotyledon [36]. Different from Arabidopsis, starch in the endosperm is accumulated in rice seeds during germination and seedling establishment [19]. The $\alpha$-amylase can help release soluble glucans, which are substrates for further degradation. There are drastic morphological changes during seed germination, where a tiny seed transforms into a normal seedling, including large-scale changes and regulation of gene expression. Under salt stress, $\mathrm{H}_{2}$ accelerated the seed germination of 
rice by increasing energy resources [28]. However, the intricate mechanism associated with its responses to abiotic stress and plant growth and development is still a subject of great interest. To investigate the possible roles of $\mathrm{H}_{2}$ in seed germination, we explored whether the application of HRW upgrades seed vitality to promote seed germination in cucumber. The potential mechanisms during this process were also investigated. Deeper insights into the interplay of various phytohormones with $\mathrm{H}_{2}$ at a signaling level will provide a road map for addressing the problem more holistically.

\section{Materials and Methods}

\subsection{Preparation of Hydrogen-Rich Water}

Purified hydrogen gas $(99.99 \%, v / v)$ generated from a hydrogen gas generator (QL300, Saikesaisi Hydrogen Energy Co., Ltd., Jinan, China) was bubbled into 2 L of distilled water (room temperature) at a rate of $300 \mathrm{~mL} \cdot \mathrm{min}^{-1}$ for $3 \mathrm{~h}$. Then, the prepared HRW was analyzed by a dissolved hydrogen portable meter (ENH-1000, Trustlex Co., Led, Tokyo, Japan). In our experimental conditions, the $\mathrm{H}_{2}$ concentration was $0.45 \mathrm{mM}$ and maintained at a relative constant level at $25^{\circ} \mathrm{C}$ for at least $12 \mathrm{~h}$, which was defined as $100 \%$ HRW. Finally, HRW was immediately diluted to various concentrations $(1,10,25,50,75$, and 100\%).

\subsection{Plant Material and Hydrogen-Rich Water Treatment}

Cucumber (Cucumis sativus L. 'Xinchun No. 4') seeds were acquired from Lanfeng Seed Company, Lanzhou City, China. The selected seeds were without physical damage, without disease, and of similar size. The seeds used as experimental materials were washed. The surface of the seeds was sterilized with $0.1 \%$ sodium hypochlorite for $10 \mathrm{~min}$ and rinsed with distilled water. Then, 0 (distilled water, the control), 1, 10, 25, 50, 75, and 100\% HRW concentrations were used for seed treatment. The experiments were conducted at $25{ }^{\circ} \mathrm{C}$ in dark condition. Samples were placed in $14 \mathrm{~cm}$ petri dishes on two layers of filter paper saturated with $10 \mathrm{~mL}$ distilled water or different concentrations of hydrogen-rich water for $48 \mathrm{~h}$. The solution was replaced with each concentration of water every day. Meanwhile, the number of germinated seeds was counted. Then, the seeds of each treatment were freshly preserved at $0,4,8,12,24,36$, and $48 \mathrm{~h}$ after treatment.

\subsection{Determination of Morphological Indexes and Seed Vitality}

When the germ length exceeded half of the length of seeds, it was defined as germination [28]. The germination rate was calculated, and the germ length was measured from the root tip to the germ and hypocotyl junction at $0,4,8,12,24,36$, and $48 \mathrm{~h}$.

The fresh weight of 20 cucumber seeds was determined, and the average fresh weight in each treatment was calculated. Then, the seeds were baked dry at $80{ }^{\circ} \mathrm{C}$ for $48 \mathrm{~h}$ to calculate the average dry weight [37].

In addition, the germination index (GI) was calculated according to GI $=\sum$ (Gt/Tt), where Gt is the number of the germinated seeds in the hour. The seed vitality index (VI) was determined according to the formula VI $=$ GI $\times$ seedling dry weight [38].

The cucumber seeds were exposed to different concentrations of $\operatorname{HRW}(0,1,10,25,50$, 75 , and $100 \%$ ) and cut into two parts along the center line of the seeds within $48 \mathrm{~h}$. The cut seeds were immersed under $0.5 \%(w / v)$ triphenyl tetrazolium chloride (TTC) solution in a petri dish and incubated at $30{ }^{\circ} \mathrm{C}$ for $1 \mathrm{~h} \mathrm{[39].} \mathrm{Then,} \mathrm{the} \mathrm{TTC} \mathrm{solution} \mathrm{was} \mathrm{removed} \mathrm{with}$ distilled water. The colors of the seeds were observed and photographed at $48 \mathrm{~h}$ [28]. Seed vitality was determined by TTC solution; the darker the red, the stronger the seed vitality. Ninety seeds were analyzed for each treatment with three replicates.

\subsection{Determination of Soluble Sugar, Soluble Protein, and Starch Contents}

The soluble sugar content was measured according to [40]. Fresh cucumber seeds $(0.2 \mathrm{~g})$ were milled into homogenate with distilled water and placed in a test tube. The mixture comprised distilled water $(1.5 \mathrm{~mL}), 0.5 \mathrm{~mL}$ extracting solution, $5.0 \mathrm{~mL} \mathrm{H}_{2} \mathrm{SO}_{4}$ $(98 \%)$, and $0.5 \mathrm{~mL}$ of ethylacetate anthrone reagent in $25 \mathrm{~mL}$ tubes. Then, the mixture was 
heated in a boiling water bath for $1 \mathrm{~min}$. The absorbance was recorded at $630 \mathrm{~nm}$ using a spectrophotometer.

For determination of the soluble starch content, samples $(0.2 \mathrm{~g})$ were ground and extracted in $2 \mathrm{~mL}$ distilled water. After sufficient grinding, $3.2 \mathrm{~mL} 60 \%$ perchloric acid was added and grinded for $10 \mathrm{~min}$. The homogenate was then centrifuged at $3000 \times g$ for $5 \mathrm{~min}$ at room temperature and then filtered into a $100 \mathrm{~mL}$ volumetric flask. The liquid was mixed evenly by shaking after constant volume. Then, the extracting solution $(0.5 \mathrm{~mL})$, $3 \mathrm{~mL}$ of distilled water, and $2 \mathrm{~mL}$ iodine reagent were mixed together in a $25 \mathrm{~mL}$ test tube. The mixture was maintained at a constant volume of $10 \mathrm{~mL}$ after standing for $5 \mathrm{~min}$, and the absorbance was measured at $660 \mathrm{~nm}$ at room temperature [40].

For determination of the soluble protein content, $0.2 \mathrm{~g}$ samples were ground and extracted with $5 \mathrm{~mL}$ of distilled water. The homogenate was then centrifuged at 12,000 $\times g$ at $4{ }^{\circ} \mathrm{C}$ for $20 \mathrm{~min}$. Then, $1 \mathrm{~mL}$ of the supernatant and $5 \mathrm{~mL}$ of Coomassie brilliant blue were mixed together. The absorbance at $595 \mathrm{~nm}$ was measured after $2 \mathrm{~min}$ [41].

\subsection{Determination of Total Amylase and $\alpha$ - and $\beta$-Amylase Activities}

The activities of $\alpha$ - and $\beta$-amylase and total amylase in cucumber seeds were analyzed by a amylase determination kit (Beijing Biolab Technology Co., Ltd., Beijing, China) according to the manufacturer's instructions. Samples $(0.1 \mathrm{~g})$ were ground and extracted in $1 \mathrm{~mL}$ of distilled water. The homogenate was constant kept for $10 \mathrm{~min}$, then shaken and extracted sufficiently at room temperature. The homogenate was then centrifuged at $3000 \times g$ at $25{ }^{\circ} \mathrm{C}$ for $10 \mathrm{~min}$. The supernatant was made up to the volume of $10 \mathrm{~mL}$ by adding distilled water and mixed evenly to be used as the amylase stock solution. The activities of $\alpha$ - and $\beta$-amylase and total amylase were measured according to Table 1 . Their activities were calculated by following the formulas:

Table 1. The measurement of amylase activities.

\begin{tabular}{|c|c|c|c|c|}
\hline \multirow{2}{*}{ Reagent Name $(\mu \mathrm{L})$} & \multicolumn{2}{|c|}{ Determination of $\alpha$-Amylase Activities } & \multicolumn{2}{|c|}{ Determination of Total Amylase Activities } \\
\hline & The Control Tube & The Test Tube & The Control Tube & The Test Tube \\
\hline Amylase stock solution & 250 & 250 & & \\
\hline \multicolumn{5}{|c|}{ In $70{ }^{\circ} \mathrm{C}$ water bath for $15 \mathrm{~min}$ and cooled rapidly } \\
\hline Amylase diluent & & & 250 & 250 \\
\hline Distilled water & 250 & & 250 & \\
\hline Reagent 2 & & 250 & & 250 \\
\hline \multicolumn{5}{|c|}{ At $40^{\circ} \mathrm{C}\left( \pm 0.5^{\circ} \mathrm{C}\right)$ constant temperature water bath for $5 \mathrm{~min}$} \\
\hline Reagent 1 & 500 & 500 & 500 & 500 \\
\hline
\end{tabular}

The mixture was shaken sufficiently in a $95{ }^{\circ} \mathrm{C}$ water bath for $5 \mathrm{~min}$ and cooled rapidly. The absorbance was measured at $540 \mathrm{~nm}$ and marked as A1, A2, A3, and A4 from left to right.

The $\alpha$-amylase activity $(\mathrm{mg} / \mathrm{min} / \mathrm{g}$ fresh weight $)=1.075 \times(\mathrm{A} 2-\mathrm{A} 1+0.1778) / 0.1$.

The total amylase activity $(\mathrm{mg} / \mathrm{min} / \mathrm{g}$ fresh weight $)=5.375 \times(\mathrm{A} 4-\mathrm{A} 3+0.1778) / 0.1$.

The $\beta$-amylase activity $(\mathrm{mg} / \mathrm{min} / \mathrm{g}$ fresh weight $)=$ the total amylase activity - the $\alpha$-amylase activity.

\subsection{Total RNA Extraction}

Total RNA in seeds was extracted using TRIzol reagent. In brief, the samples $(0.2 \mathrm{~g})$ were ground into powder with liquid nitrogen. TRIzol $(1 \mathrm{~mL})$ was added to the powder and incubated for $10 \mathrm{~min}$ at $4{ }^{\circ} \mathrm{C}$. Then, chloroform $(200 \mu \mathrm{L})$ was added and incubated for $5 \mathrm{~min}$. The misture was centrifugated at $12,000 \times \mathrm{g}$ for $15 \mathrm{~min}$ at $4{ }^{\circ} \mathrm{C}$, and the supernatant was collected. An equal volume of isopropanol was added to the supernatant and incubated at $-20{ }^{\circ} \mathrm{C}$ for more than $1 \mathrm{~h}$. The supernatant was collected into the adsorption column after washing with $75 \%$ ethanol twice. Finally, the RNA was dissolved with RNase-free $\mathrm{ddH}_{2} \mathrm{O}$. The extracted total RNA was used to convert into single-stranded cDNA following the manufacturer's recommendations. RNA quality and quantity were measured using a 
NanoDrop spectrophotometer and an Agilent 2100 spectrophotometer. The 260/280 ratio was 2.0-2.2, and RNA integrities were greater than 8.0 for all samples.

\subsection{Determination of AMY, BMY, SS4, and SS3 Gene Expression}

Quantitative real-time PCR (qRT-PCR) assays were used to determine the relative expression level of each gene by StepOne Real-Time PCR System (ABI StepOne Plus, California, USA). The expression of starch-related genes (including AMY (alpha amylase) and BMY (beta amylase)) and sucrose-related genes (including SS4 (sucrose synthase 4) and SS3 (sucrose synthase 3)) were determined. The gene-specific primers for AMY, BMY, SS4, and SS3 genes were designed according to CDS sequence. Table 2 lists the primer sequences used in the study. Each reaction ( $20 \mu \mathrm{L}$ total volume) consisted of $10 \mu \mathrm{L}$ of $2 \times$ qPCR mix, $1 \mu \mathrm{M}$ of diluted cDNA, and $10 \mu \mathrm{M}$ of forward and reverse primers. The PCR cycling conditions were as follows: $95^{\circ} \mathrm{C}$ for $5 \mathrm{~min}$, followed by 40 cycles of $95^{\circ} \mathrm{C}$ for $10 \mathrm{~s}$ and $60{ }^{\circ} \mathrm{C}$ for $30 \mathrm{~s}$. The fluorescence data were collected during the $60{ }^{\circ} \mathrm{C}$ step. The cucumber actin gene was used as an internal gene [42]. The relative expression of the genes was calculated using the $2^{-\Delta \Delta c t}$ method [43]. Four replicates were set for all assays.

Table 2. Primers used for relative quantitative real-time PCR assays.

\begin{tabular}{|c|c|c|c|c|c|}
\hline Gene & Full Gene Name & Accession No. ${ }^{a}$ & Primer Pair $\left(5^{\prime}-3^{\prime}\right)$ & \multicolumn{2}{|c|}{ Schematic Diagram } \\
\hline \multirow{2}{*}{$A M Y$} & \multirow{2}{*}{ The alpha amylase } & \multirow{2}{*}{ XM_004151148 } & F:CACGGTTATTACACCCAGGACT & \multicolumn{2}{|l|}{$835 \mathrm{bp} \triangleright \mathrm{F}$} \\
\hline & & & R:TAAATCATCTTCGTTGCCCAT & $1 \mathrm{bp} \quad \mathrm{R} \triangleleft 897 \mathrm{bp}$ & $1347 \mathrm{bp}$ \\
\hline \multirow{2}{*}{$B M Y$} & \multirow{2}{*}{ The beta amylase } & \multirow{2}{*}{ XM_004138543 } & F:GGTGTCAAGTGGTAGCAACAATAAC & $179 \mathrm{bp} \triangleright \mathrm{F}$ & \\
\hline & & & R:TGTCCTCTCTTTCTCTTCTAATGGTCT & $\mathrm{R} \triangleleft 291 \mathrm{bp}$ & $2163 \mathrm{bp}$ \\
\hline \multirow{2}{*}{ SS4 } & \multirow{2}{*}{ The sucros synthase 4} & \multirow{2}{*}{ LOC101205508 } & F: CCTGAACTTCTGCCATCTGCTATC & $1677 \mathrm{bp} \bullet$ & \\
\hline & & & R: ACTGGGTGTGGCTTTGGTGAATG & $\mathrm{R} \triangleleft 1769 \mathrm{bp}$ & $10,874 \mathrm{bp}$ \\
\hline \multirow{2}{*}{ SS3 } & \multirow{2}{*}{ The sucros synthase 4} & \multirow{2}{*}{ LOC101213925 } & F: ATGGGAGCGTTCAATGACTGGAAG & $\begin{array}{c}287 \mathrm{bp} \triangleright \mathrm{F} \\
\quad|\quad|\end{array}$ & ل \\
\hline & & & R: ATGAATCTGACACGACCACCAATCC & $1 \mathrm{bp} \mathrm{R} 4398 \mathrm{bp}$ & $21,756 \mathrm{bp}$ \\
\hline \multirow{2}{*}{$A C T$} & \multirow{2}{*}{ Actin } & \multirow{2}{*}{ AB010922 } & F: TTCTGGTGATGGTGTGAGTC & $113 \mathrm{bp} \triangleright \mathrm{F}$ & \\
\hline & & & R: GGCAGTGGTGGTGAACATG & $\mathrm{R} \triangleleft 264 \mathrm{bp}$ & $463 \mathrm{bp}$ \\
\hline
\end{tabular}

a NCBI accession.

\subsection{Statistical Analysis}

The values (mean \pm standard error (SE)) are the average of three independent experiments $(n=3)$. Statistical differences among treatments were analyzed by Tukey-Kramer's multiple comparison test or $t$-test $(p<0.05)$. The analysis of variance (ANOVA) of data was performed by the Statistical Analysis System (SPSS, Version 13.00; SPSS Inc., Chicago, IL, USA) software.

\section{Result}

\subsection{Effect of HRW on Seed Germination in a Dose-Dependent Manner}

To understand the roles of $\mathrm{H}_{2}$ in seed germination, different concentrations of HRW $(1,10,25,50,75$, and $100 \%)$ were used to treat cucumber seeds. As shown in Figure 1, HRW treatment significantly promoted seed germination rates compared to the control $(0 \%)$, and the effects were dose-dependent. Among the different concentrations of HRW, the maximum germination rate $(95.9 \%)$ and germ length $(21.4 \mathrm{~mm})$ were observed with $75 \%$ HRW treatment (Figure 1A). The germination index and vitality index presented a trend that first increased and then decreased with the increase in HRW concentrations, reaching the peak when HRW level was 75\% (Figure 1B,C). As shown in Figure 1D, the number of red-stained cucumber seeds was significantly increased by HRW treatment. Compared with the control, $75 \%$ HRW treatment resulted in 30.25\% higher red seed number at $48 \mathrm{~h}$, suggesting that HRW improved seed vitality (Figure 1D). The seed vitality was determined 
by TTC solution; the darker the red, the stronger the seed vitality. Therefore, $75 \%$ HRW treatment was used for further studies during the seed germination process.

\subsection{Effect of HRW on Seed Germination in a Time-Dependent Manner}

Figure $2 \mathrm{~A}$ shows that the germination rate increased gradually during the whole germination process and was close to $100 \%$ at $48 \mathrm{~h}$. Nevertheless, $75 \%$ HRW treatment significantly increased germination rate at $12 \mathrm{~h}$ after treatment in comparison with the control.
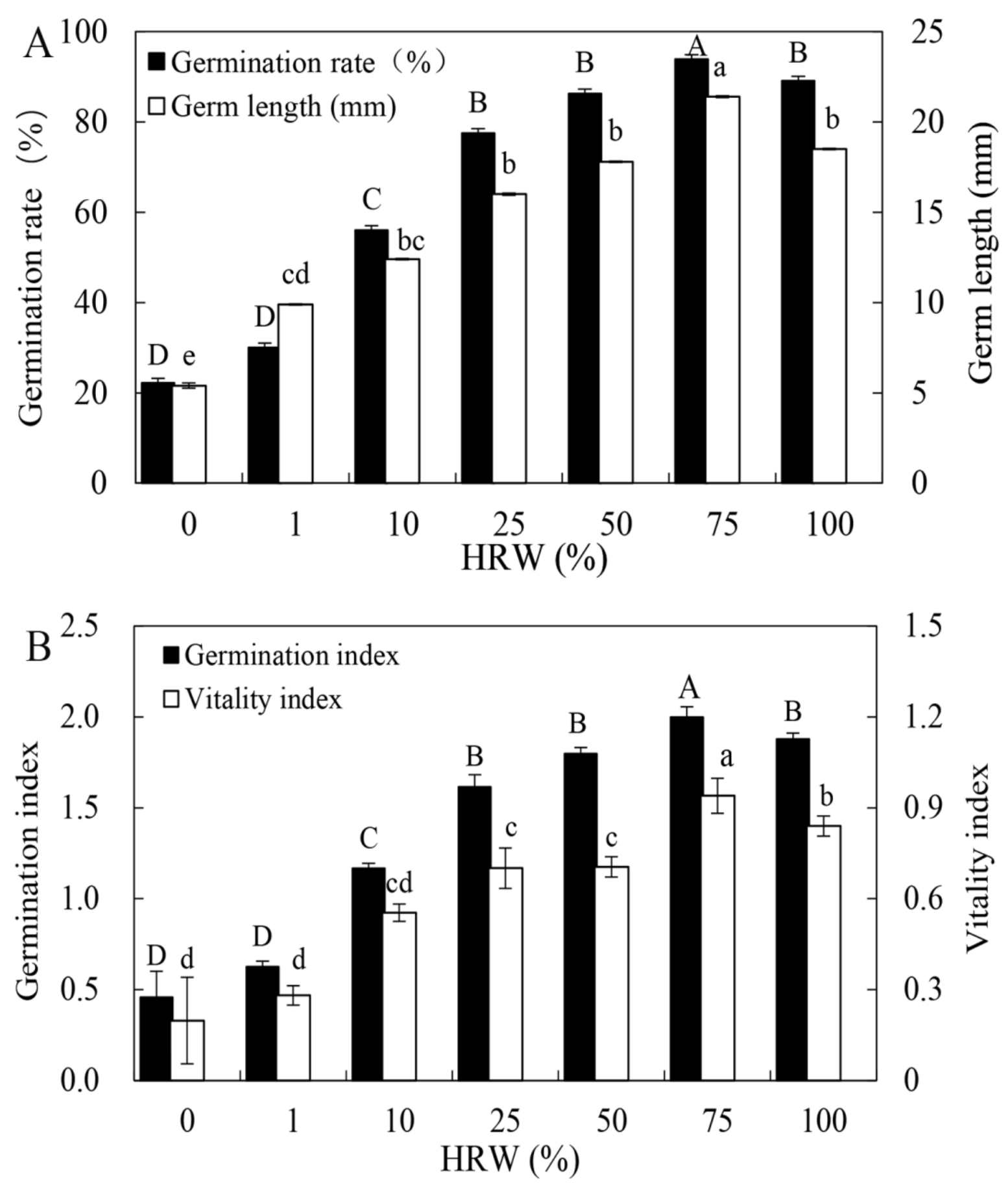

Figure 1. Cont. 

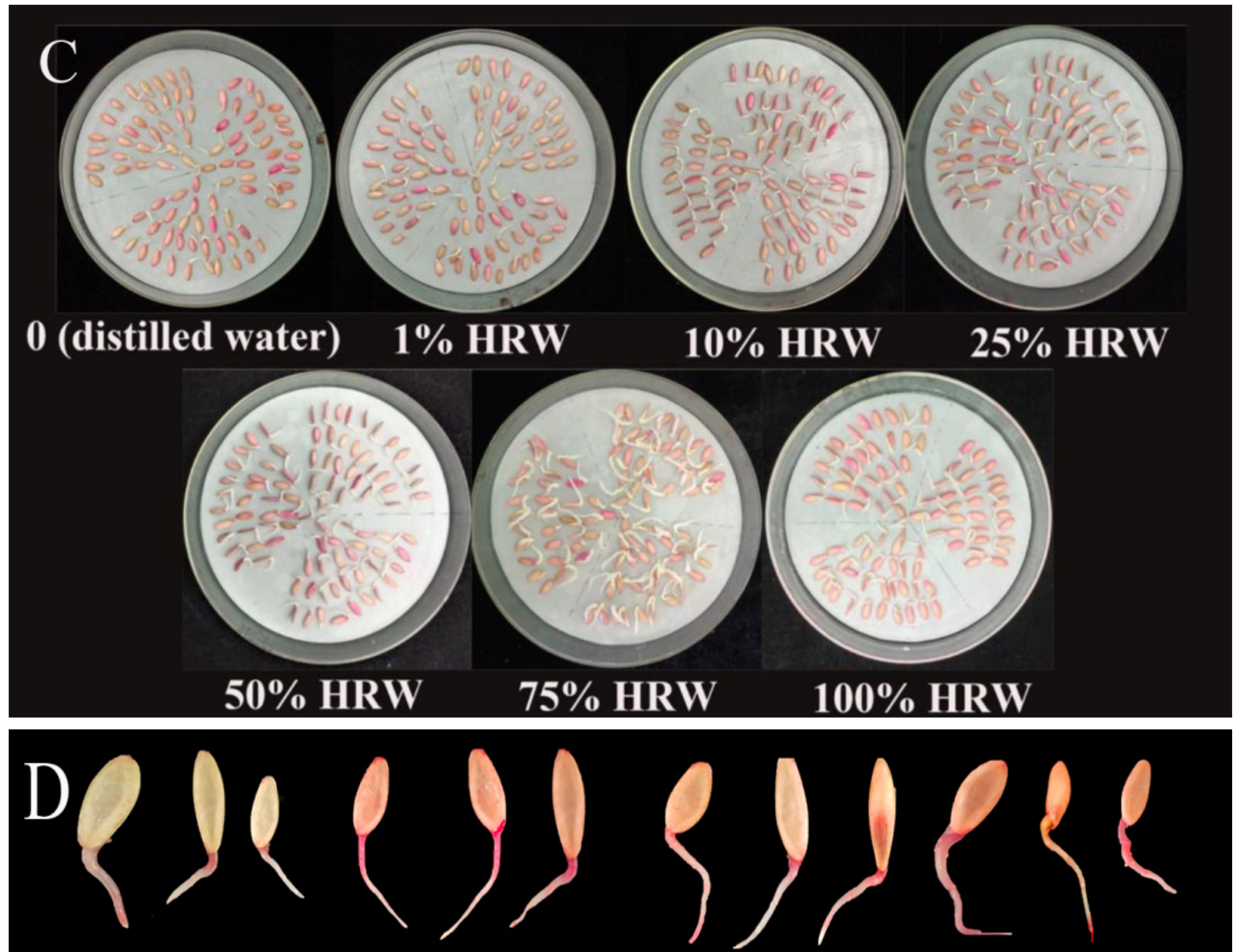

\section{0 (distilled water) $1 \%$ (HRW)}

$10 \%(\mathrm{HRW})$

$25 \%(\mathrm{HRW})$
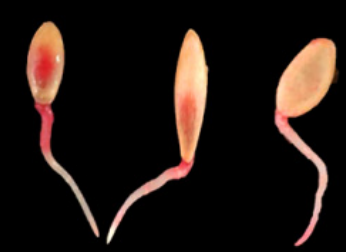

$50 \%(\mathrm{HRW})$

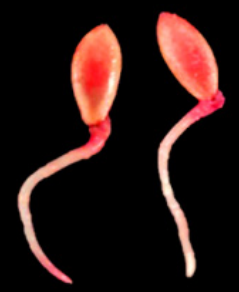

75\%(HRW)
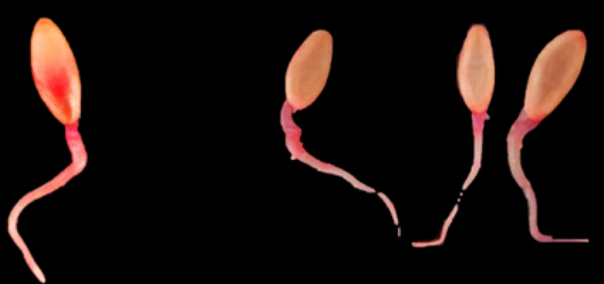

$100 \%(\mathrm{HRW})$

Figure 1. Changes in the germination rate and germ length (A), germination index and activity index (B), and seed vitality (C,D) in cucumber with different concentrations of HRW at $48 \mathrm{~h}$. The seed vitality was determined by TTC solution (D); the darker the red, the stronger the seed vitality. The concentrations of $\mathrm{HRW}$ were $0,1,10,25,50,75$, and 100\%. The error bars denote the standard errors $(n=3)$. The different uppercase letters $(A-D)$ above the black columns in $(\mathbf{A}, \mathbf{B})$ indicate significant differences $(p<0.05)$ of germination rate and germination index, and the different lowercase letters $(\mathrm{a}, \mathrm{b}, \mathrm{c}$, and d) above the white columns in $(\mathbf{A}, \mathbf{B})$ indicate significant differences $(p<0.05)$ of germ length and vitality index according to one-way ANOVA and Tukey-Kramer's multiple range test. HRW: hydrogen-rich water.

Similar to the germination rate, Figure 2B illustrates an increasing trend of the germ length throughout the test period, especially from 8 to $12 \mathrm{~h}$. Moreover, the germ length of seeds treated with 75\% HRW significantly increased from 12 to $48 \mathrm{~h}$ and reached the maximum value at $48 \mathrm{~h}$. 
The germination index and vitality index in seeds treated with 75\% HRW increased gradually and peaked on $12 \mathrm{~h}$, followed by a gradual decrease until the end of germination (Figure 2C,D). Additionally, compared to the control, the germination index was increased approximately 42.4 and $34.8 \%$ by $75 \%$ HRW treatment at 12 and $24 \mathrm{~h}$, respectively (Figure 2C). Similarity, in comparison with the control, the vitality index was improved approximately $189.3,94.8,49.67$, and $55.45 \%$ by $75 \%$ HRW treatment at $12,24,36$, and $48 \mathrm{~h}$, respectively (Figure 2D).

As shown in Figure 2E, the fresh weight for both the control and seeds treated with $75 \%$ HRW tended to increase throughout the germination period. However, the fresh weight of seeds treated with $75 \% \mathrm{HRW}$ was higher than that for the control at $36 \mathrm{~h}$, resulting in a higher level of fresh weight. Compared to the control, $75 \%$ HRW treatment increased the dry weight by 27.47 and $98.64 \%$ after 12 and $48 \mathrm{~h}$ of germination, respectively (Figure 2F).
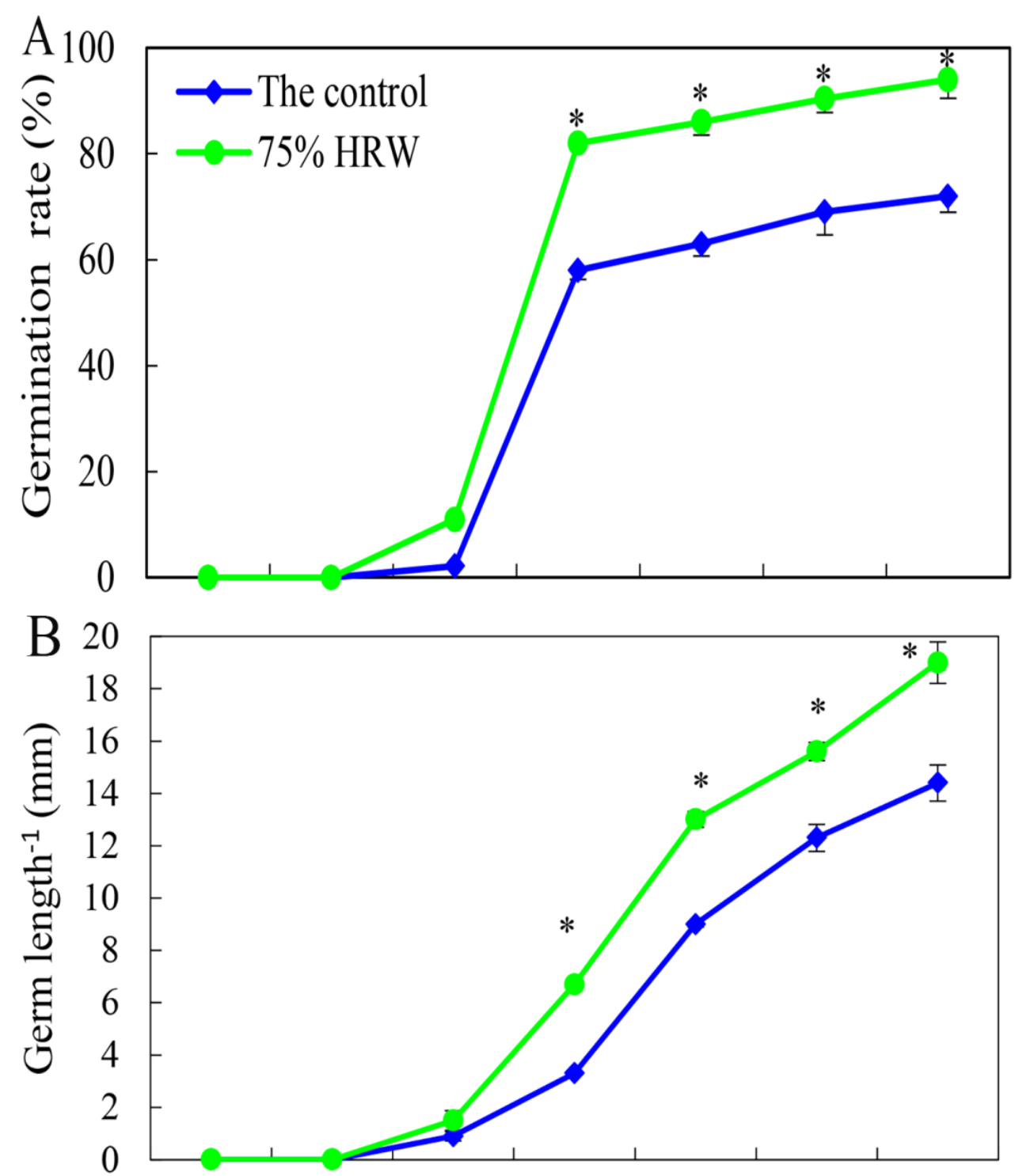

Figure 2. Cont. 

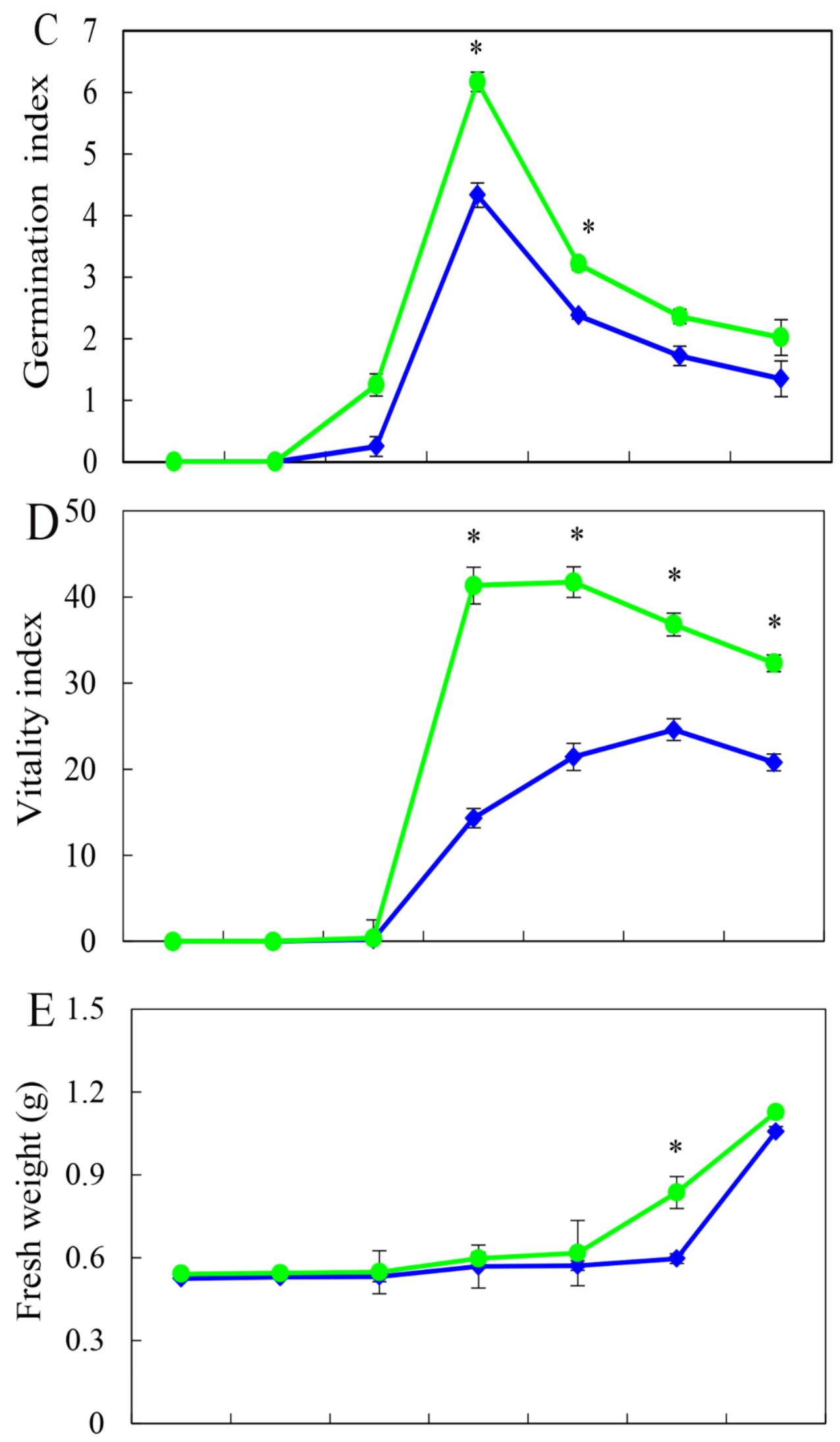

Figure 2. Cont. 


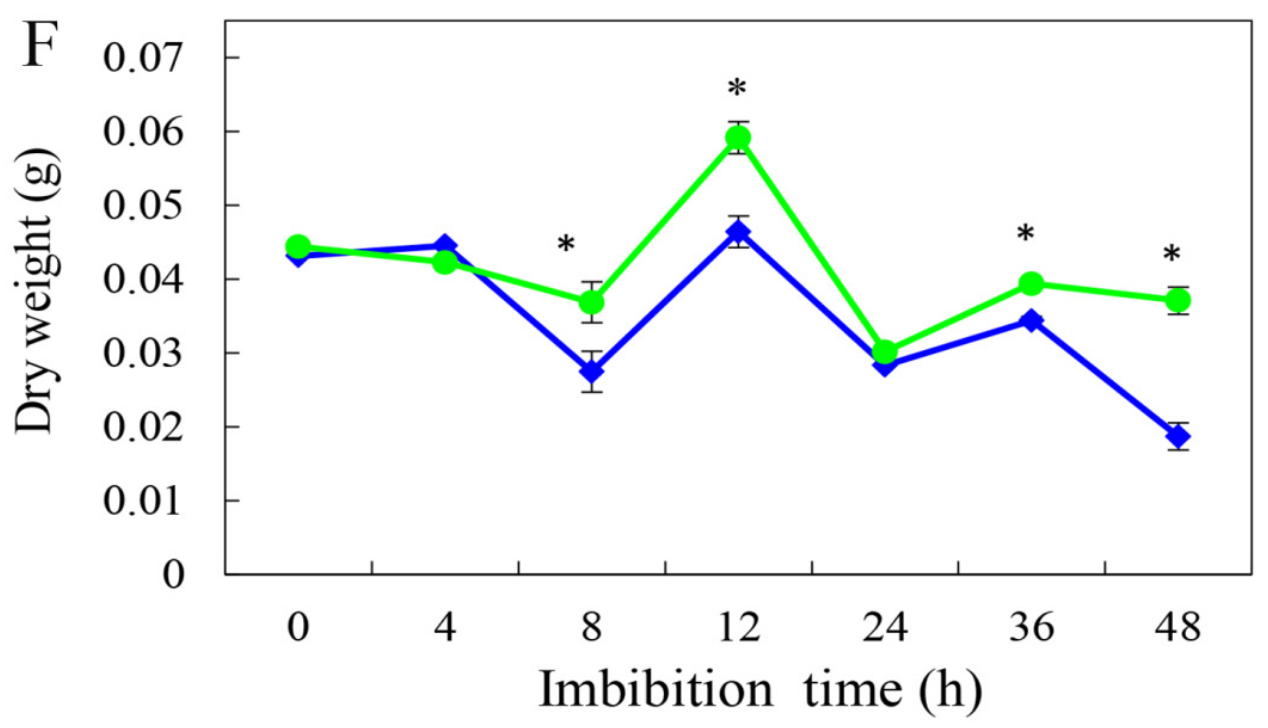

Figure 2. Changes in germination rate (A), germ length (B), germination index (C), vitality index (D), fresh weight (E), and dry weight (F) in cucumber with or without $75 \%$ HRW treatment during imbibition at $0,4,8,12,24,36$, and $48 \mathrm{~h}$. The values (mean \pm standard error (SE)) are the average of three independent experiments $(\mathrm{n}=3)$. The asterisks denote Turkey-Kramer's $t$-test significance under different treatments at the same time: ${ }^{*} p<0.05$, h: hours, HRW: hydrogen-rich water.

\subsection{Effect of HRW on Total Soluble Sugar, Total Soluble Protein, and Total Soluble Starch Contents during Germination}

More soluble sugar, protein, and starch were accumulated in seeds treated with $75 \%$ HRW than in the control seeds (Figure 3). The soluble sugar content in the control and seeds treated with $75 \% \mathrm{HRW}$ initially increased and then decreased, attaining the maximum at $8 \mathrm{~h}$ (Figure 3A). The soluble sugar contents with and without $75 \%$ HRW treatment declined after $8 \mathrm{~h}$, and a significant difference was observed between the control and seeds treated with $75 \%$ HRW from 8 to $48 \mathrm{~h}$ (Figure 3A). Similar to the soluble sugar, the tendency of soluble protein increased first and then decreased, obtaining the maximum at $8 \mathrm{~h}$ (Figure 3B). Significant difference was observed between the control and seeds treated with $75 \%$ HRW from 8 to $48 \mathrm{~h}$ (Figure 3B). The soluble starch content remained at a steady level in all treatment groups from 0 to $8 \mathrm{~h}$, after which it declined (Figure 3C). By contrast, from 24 to $48 \mathrm{~h}$, the starch content was higher in the control than in seeds treated with $75 \%$ HRW (Figure 3C). Therefore, the contents of soluble sugar, soluble protein, and starch were increased by $75 \% \mathrm{HRW}$ treatment, which might promote seed germination.

\subsection{Effect of HRW on Total Amylase and $\alpha$ - and $\beta$-Amylase Activities during Germination}

Figure 4 shows the changes in amylolytic enzyme activities. The activities of total amylase and $\beta$-amylase enzymes in the control and seeds treated with $75 \% \mathrm{HRW}$ first decreased and then increased throughout the test period, attaining the maximum value at $36 \mathrm{~h}$ (Figure $4 \mathrm{~A}, \mathrm{~B})$. The activities of total amylase and $\beta$-amylase in seeds treated with $75 \% \mathrm{HRW}$ were significantly higher than those in the control at 8 and $36 \mathrm{~h}$ (Figure 4A,B). There was a significant increase in $\alpha$-amylase activity in seeds treated with $75 \% \mathrm{HRW}$ from 24 to $48 \mathrm{~h}$, and the highest $\alpha$-amylase activity was detected at $8 \mathrm{~h}$ after treatment, being about 1.35 -fold the activity at $0 \mathrm{~h}$. The $\alpha$-amylase activity in the control changed almost coordinately with that in the seeds with HRW treatment. However, the $\alpha$-amylase activity levels were higher in HRW-treated seeds than in the control seeds, particularly after $12 \mathrm{~h}$ (Figure 4C). 

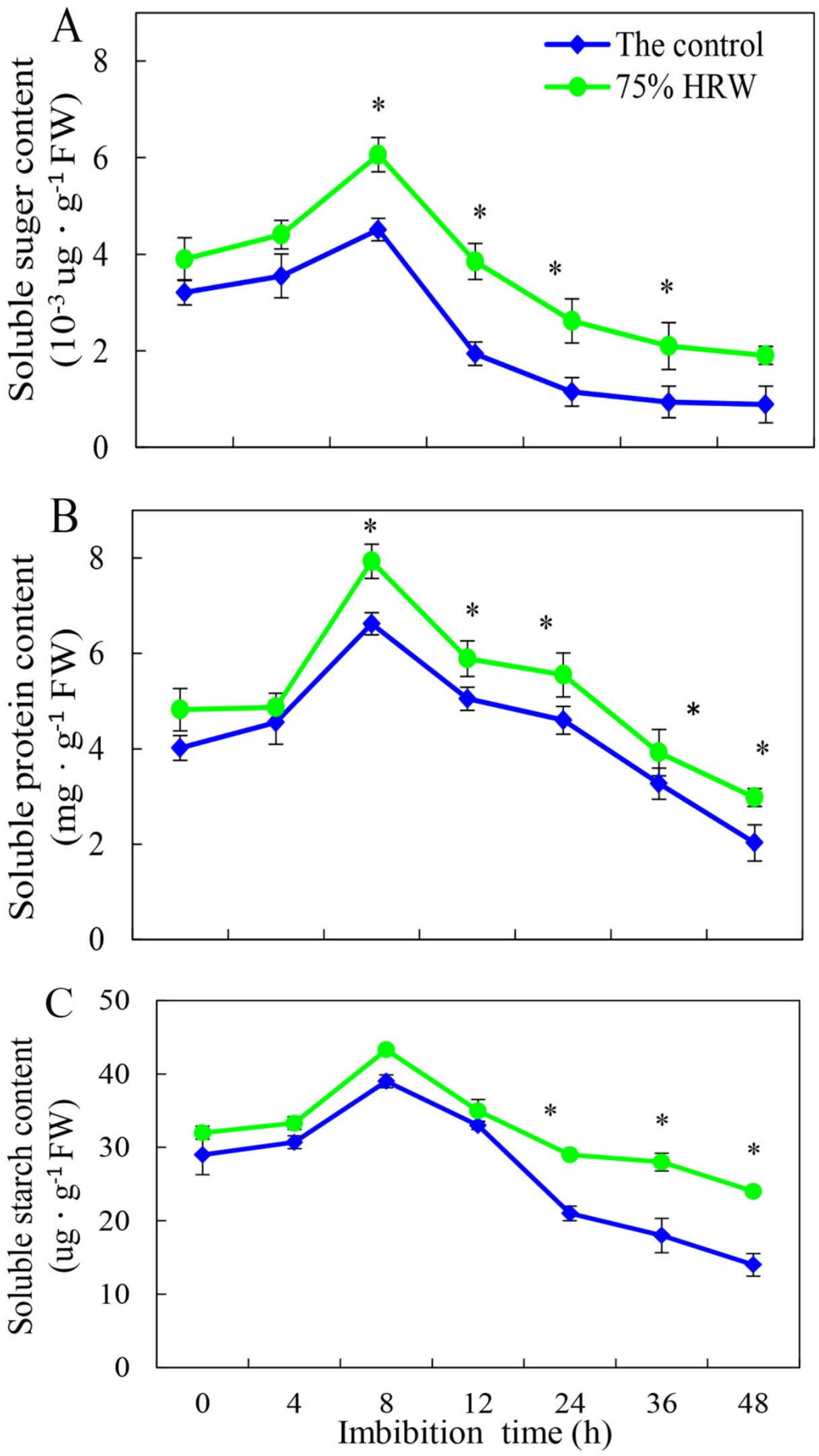

Figure 3. Changes in the contents of soluble sugars (A), soluble protein (B), and soluble starch (C) of cucumber seed with or without $75 \%$ HRW treatment during $48 \mathrm{~h}$ germination. Data are mean $\pm \mathrm{SE}$ of three independent experiments. The asterisks denote Turkey-Kramer's $t$-test significance under different treatments at the same time: ${ }^{*} p<0.05$, h: hours, HRW: hydrogen-rich water. 

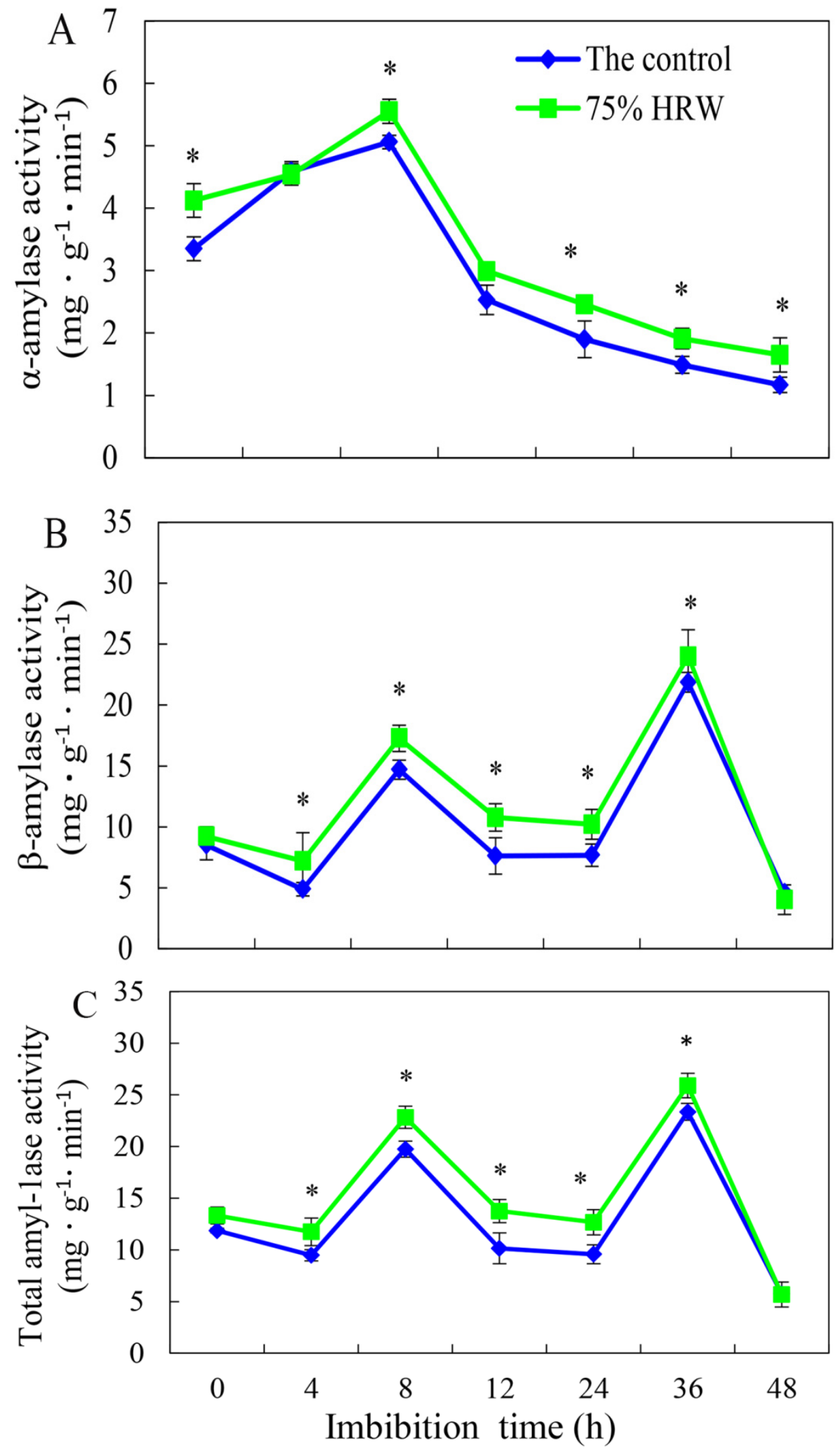

Figure 4. Changes in enzyme activities in cucumber seed with or without $75 \%$ HRW treatment during imbibition at $0,4,8,12,24,36$, and $48 \mathrm{~h}$. (A) $\alpha$-amylase activity, (B) $\beta$-amylase activity, and (C) Total amylase activity. Data are mean \pm SE of three independent experiments. The asterisks denote Turkey-Kramer's $t$-test significance under different treatments at the same time: ${ }^{*} p<0.05$, h: hours, HRW: hydrogen-rich water. 


\subsection{Effect of HRW on AMY, BMY, SS3, and SS4 Gene Expression during Germination}

To gain insight into the mechanism by which $\mathrm{H}_{2}$ affects amylase activity, the expression levels of $A M Y, B M Y, S S 3$, and $S S 4$ genes were examined at $0,4,8,12,24,36$, and $48 \mathrm{~h}$ after treatment. HRW significantly increased their expression levels, particularly at $36 \mathrm{~h}$ (Figure 5). AMY gene was significantly upregulated by $75 \% \mathrm{HRW}$ treatment compared to the control at 8,36 , and $48 \mathrm{~h}$ (Figure $5 \mathrm{~A}$ ). Similar to $A M Y$ gene, the express levels of $B M Y$ gene were also significantly increased at 8,36 , and $48 \mathrm{~h}$ (Figure $5 \mathrm{~B}$ ). This suggests that amylase may not only be used for the degradation of starch to provide energy during seed germination but also play important roles in other biological processes. Compared to the control, 75\% HRW treatment significantly upregulated the expression level of SS4 gene at 4,36 , and $48 \mathrm{~h}$, increasing by $74.2,98.8$, and $50.3 \%$, respectively (Figure $5 \mathrm{C}$ ). The SS3 gene expression levels initially increased and then decreased, obtaining the maximum level at $36 \mathrm{~h}$, and was significantly upregulated at 36 and $48 \mathrm{~h}$ (Figure 5D). Combined with the above results, the upregulation of $A M Y, B M Y, S S 4$, and $S S 3$ genes may be involved in HRW-induced seed germination.
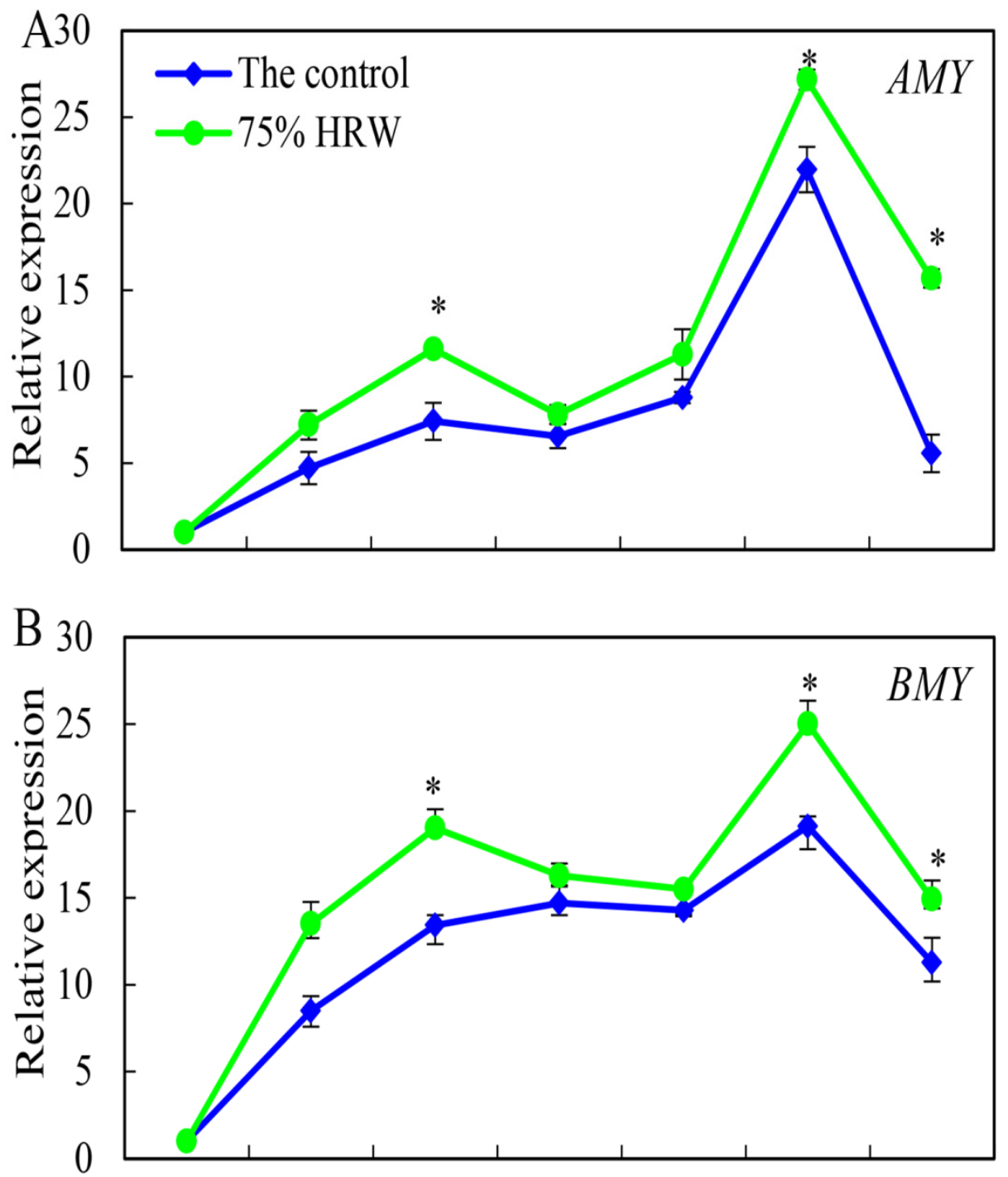

Figure 5. Cont. 

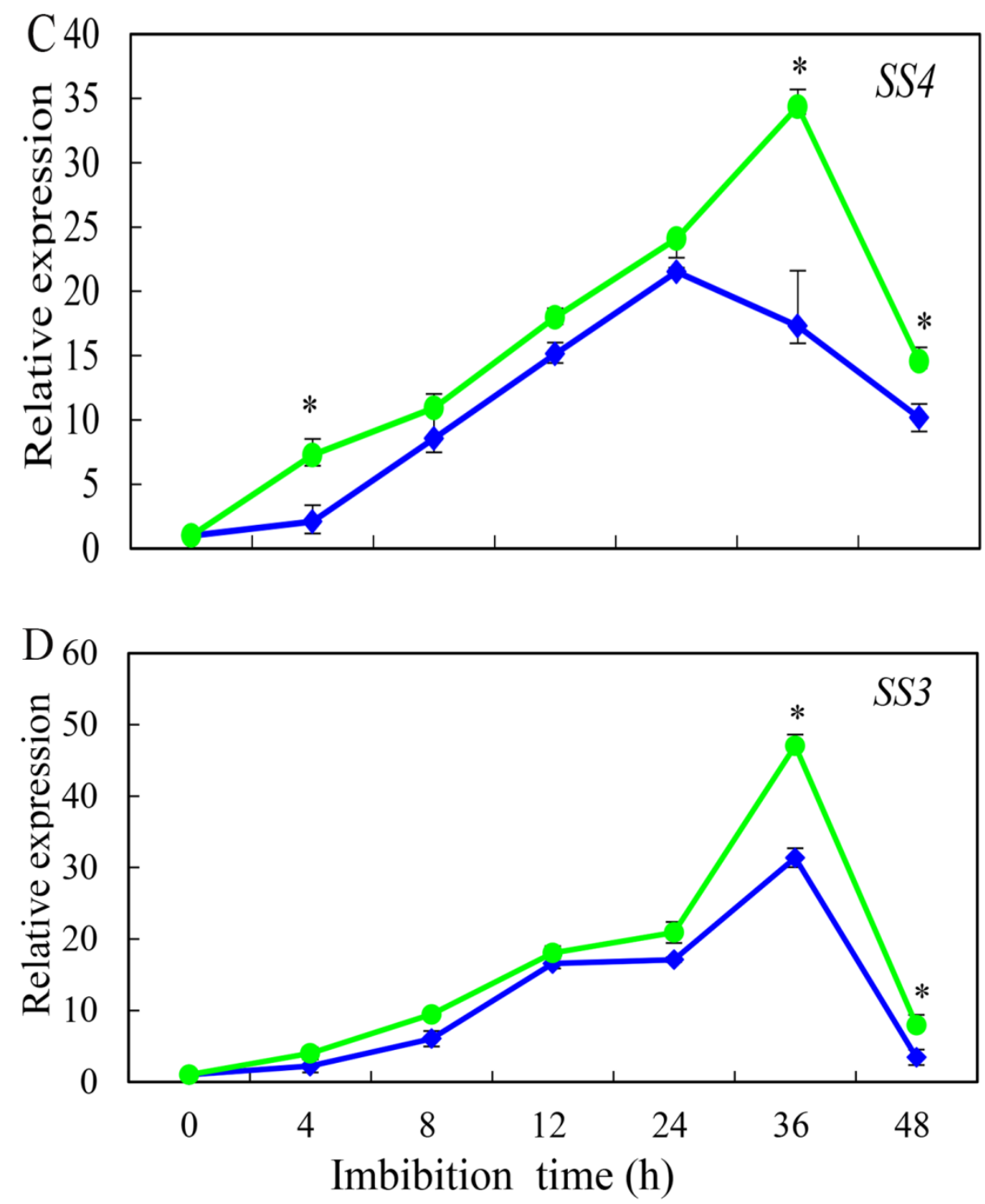

Figure 5. Expression of $A M Y(\mathbf{A}), B M Y(\mathbf{B}), S S 4(\mathbf{C})$, and $S S 3$ (D) genes in cucumber seed at 0, 4, 8, 12, 24,36 , and $48 \mathrm{~h}$ after exposure to different treatments. Treatments consisted of control (distilled water) and $75 \%$ HRW treatment. Data are mean \pm SE of three independent experiments. The asterisks denote Turkey-Kramer's $t$-test significance under different treatments at the same time: ${ }^{*} p<0.05$, h: hours, HRW: hydrogen-rich water. AMY: alpha amylase, BMY: beta amylase, SS4: sucrose synthase 4, SS3: sucrose synthase 3.

\section{Discussion}

Seed germination includes a series of physical and metabolic events. It is a complex and crucial process that determines seedling establishment [44]. As an important gaseous regulator, $\mathrm{H}_{2}$ is involved in various aspects of plant growth and development. Here, the current study found that $75 \%$ HRW treatment could increase seed germination rate, germ length, germination index, activity index, fresh weight, and dry weight in cucumber (Figures 1 and 2). Exogenous HRW treatment (from 1 to 100\%) alleviated salt stress to promote seed germination in rice, and the response of $50 \%$ concentration of HRW was the most obvious [28]. For the first time, we observed that $\mathrm{H}_{2}$ could increase cucumber seed germination under stress-free condition. Thus, our results show that HRW treatment may be a good option to promote seed germination.

Soluble sugar is an osmotic regulator and plant nutrient. Soluble sugar content was decreased from 0 to $12 \mathrm{~h}$ and increased after $12 \mathrm{~h}$ by 3-phenylpropionic acid-induced 
stress [29]. In addition, in unwatered barley seedlings, $\alpha$-amylase in leaf was increased as leaf water potential increased, resulting in the improvement of salinity stress resistance [45]. The possible reason is that soluble sugar acts as an osmotic substance in the early stage and as an energy source in the later period of seed germination. However, this hypothesis needs further studies. In our study, during seed germination in cucumber, $75 \% \mathrm{HRW}$ treatment increased soluble protein levels (Figure 3). Therefore, our results revealed that $\mathrm{H}_{2}$ may be able to increase soluble sugar and soluble protein to promote seed germination.

The AMY and BMY enzymes are very important in the starch hydrolytic process. The activity of AMY and BMY was significantly increased by Si application under PA-induced stress over 0-48 h [28]. Regarding changes in amylase activity under stress conditions, researchers have achieved two different views [46]. The activity and expression of AMY was promoted by water-induced stress in barley leaves [45]. On the contrary, the accumulation of sucrose induced by PEG in cucumber cotyledons was attributed to enhanced BMY activity [46]. Studies have also shown that the gene expressions of $A M Y$ in Cicer arietinum cotyledons [26] and $A M Y$ and BMY in Medicago sativa [47] were reduced by PEG treatment during seed germination. In our study, during seed germination, the activities of total amylase and $\alpha$ - and $\beta$ - amylase were notably enhanced by $75 \%$ HRW treatment (Figure 4 ), which is consistent with previous reports. The gene expression of $A M Y$ was enhanced under water stress in barley leaves [46]. However, our results indicated that the gene expression levels of $A M Y$ and $B M Y$ were increased by $75 \%$ HRW treatment over $48 \mathrm{~h}$ (Figure 5). A study has already explored the physiological mechanisms of $\mathrm{H}_{2}$ alleviation of abiotic stress to promote rice seed germination [28]. However, the effect of $\mathrm{H}_{2}$ on starch metabolism at the germinated stage is limited. Our results revealed that $\mathrm{H}_{2}$ might promote seed germination by regulating metabolism of starch.

There are many different kinds of sugars in plants, with fructose, glucose, and sucrose considered to be the most important ones. Fructose and glucose are monosaccharides, while only sucrose is disaccharide. However, the accumulation process of sugar is very complicated [48]. Based on previous studies, we identified the expression of SS4 and SS3 gene in cucumber seed. In our study, we also found that $75 \%$ HRW treatment upregulated the expression levels of SS4 and SS3 genes in cucumber seeds (Figure 5), indicating that $\mathrm{H}_{2}$-medicated sucrose metabolism promoted cucumber seed germination by upregulating the expression of sucrose-related genes, including SS4 and SS3. It was reported that strong light cooperation could accumulate more sucrose in watermelon [45]. In Ganlv 1, the relative expression level of AcSPS5 gene was significantly high in the later stage of fruit development [48]. In cucumber, extensive metabolism of stachyose occurred in fruit peduncles [45]. Recently, six putative $\alpha$-galactosidase genes ( $\alpha$-Gals) were found in the cucumber genome, and CsGAL2 was highly expressed in fast-growing germinating seeds [46]. Until now, studies on $\mathrm{H}_{2}$-medicated sucrose metabolism in seed germination have been scarce. Further research is required to investigate in more detail the mechanism of $\mathrm{H}_{2}$-medicated sucrose metabolism during seed germination.

\section{Conclusions}

In summary, our results revealed that the germination rate, germ length, germination index, and vitality index in cucumber exhibited a dose-dependent relationship with the increase in concentration of HRW, obtaining the maximum value with $75 \%$ HRW treatment. Moreover, the activities of $\alpha$ - and $\beta$-amylase and the total amylase were significantly improved by $75 \%$ HRW treatment. The gene expression of AMY, BMY, SS4, and SS3 was also upregulated by 75\% HRW treatment. Treatment with 75\% HRW significantly increased the content of soluble sugar, protein, and starch. These results suggest that $\mathrm{H}_{2}$ might promote cucumber seed germination by regulating sugar and starch metabolisms. Further research is required to investigate the role of $\mathrm{H}_{2}$ in modulating plant growth and development. In the future, $\mathrm{H}_{2}$ may be widely applied to regulate plant growth and development to achieve crops with high yield and better quality. 
Author Contributions: Conceptualization, W.L.; data curation, P.H. and C.L.; funding acquisition, W.L.; methodology, P.H., C.L., H.L. and Z.Z.; writing-original draft, P.H.; writing—review and editing, W.L. All authors have read and agreed to the published version of the manuscript.

Funding: This work was supported by the National Natural Science Foundation of China (Nos. 32072559, 31860568, 31560563, and 31160398); the Key Research and Development Program of Gansu Province, China (No. 21YF5WA096); the Research Fund of Higher Education of Gansu, China (No. 2018C-14 and 2019B-082); and the Natural Science Foundation of Gansu Province, China (Nos. 1606RJZA073, 1606RJZA077, and 1606RJYA252).

Data Availability Statement: The data sets supporting the results of this article are included within the article.

Conflicts of Interest: The authors declare no conflict of interest.

\section{References}

1. Mizuno, K.; Sasaki, A.T.; Ebisu, K.; Tajima, K.; Kajimoto, O.; Nojima, J.; Kuratsune, H.; Hori, H.; Watanabe, Y. Hydrogen-rich water for improvements of mood, anxiety, and autonomic nerve function in daily life. Med. Gas Res. 2018, 7, $247-255$.

2. Cui, W.T.; Gao, C.Y.; Fang, P.; Lin, G.Q.; Shen, W.B. Alleviation of cadmium toxicity in Medica gosativa by hydrogen-rich water. J. Hazard. Mater. 2013, 260, 715-724. [CrossRef] [PubMed]

3. Jin, Q.J.; Zhu, K.K.; Cui, W.T.; Xie, Y.J.; Han, B.; Shen, W.B. Hydrogen gas acts as a novel bioactive molecule in enhancing plant tolerance to paraquat induced oxidative stress via the modulation of heme oxygenase-1 signalling system. Plant Cell Environ. 2013, 36, 956-969. [CrossRef]

4. Wu, Q.; Su, N.N.; Cai, J.T.; Shen, Z.G.; Cui, J. Hydrogen-rich water enhances cadmium tolerance in Chinese cabbage by reducing cadmium uptake and increasing antioxidant capacities. J. Plant Physiol. 2015, 175, 174-182. [CrossRef]

5. $\quad$ Lin, Y.T.; Zhang, W.; Qi, F.; Cui, W.T.; Xie, Y.J.; Shen, W.B. Hydrogen-rich water regulates cucumber adventitious root development in a heme oxygenase-1/carbon monoxide-dependent manner. J. Plant Physiol. 2014, 171, 1-8. [CrossRef] [PubMed]

6. $\quad$ Su, N.N.; Wu, Q.; Liu, Y.Y.; Cai, J.T.; Shen, W.B.; Xia, K.; Cui, J. Hydrogen-rich water re-establishes ROS homeostasis but exerts differential effects on anthocyanin synthesis in two varieties of radish sprouts under UV-A irradiation. J. Agric. Food Chem. 2014, 62, 6454-6462. [CrossRef] [PubMed]

7. Zhang, J.; Hao, H.; Chen, M.; Wang, H.; Feng, Z.; Chen, H. Hydrogen-rich water alleviates the toxicities of different stresses to my celial growth in Hypsizygus marmoreus. AMB Express 2017, 7, 107. [CrossRef] [PubMed]

8. Li, C.; Gong, T.; Bian, B.; Liao, W. Roles of hydrogen gas in plants: A review. Funct. Plant Biol. 2018, 45, 8. [CrossRef]

9. Xie, Y.J.; Mao, Y.; Lai, D.W.; Zhang, W.; Shen, W.B. H2 enhances arabidopsis salt tolerance by manipulating ZAT10/12-mediated antioxidant defence and controlling sodium exclusion. PLoS ONE 2012, 7, e49800. [CrossRef] [PubMed]

10. Zhang, X.N.; Zhao, X.Q.; Wang, Z.Q.; Shen, W.B.; Xu, X.M. Protective effects of hydrogen-rich water on the photosynthetic apparatus of maize seedlings (Zea mays L.) as a result of an increase in antioxidant enzyme activities under high light stress. Plant Growth Regul. 2015, 77, 43-56. [CrossRef]

11. Xu, S.; Jiang, Y.L.; Cui, W.T.; Jin, Q.J.; Zhang, Y.H.; Bu, D.; Fu, J.Y.; Wang, R.; Zhou, F.; Shen, W.B. Hydrogen enhances adaptation of rice seedlings to cold stress via the reestablishment of redox homeostasis mediated by miRNA expression. Plant Soil 2017, 414, 53-67. [CrossRef]

12. Ren, P.; Jin, X.; Liao, W.; Wang, M.; Niu, L.; Li, X.P.; Xu, X.P.; Zhu, X.P. Effect of hydrogen-rich water on vase life and quality in cut lily and rose flowers. Hortic. Environ. Biotechnol. 2017, 58, 576-584. [CrossRef]

13. Su, J.; Nie, Y.; Zhao, G.; Cheng, D.; Wang, R.; Chen, J.; Zhang, S.; Shen, W. Endogenous Hydrogen gas delays petal senescence and extends the vase life of lisianthus cut flowers. Postharvest Biol. Technol. 2019, 147, 148-155. [CrossRef]

14. Wang, C.L.; Fang, H.; Gong, T.Y.; Zhang, J.; Niu, L.J.; Huang, D.J.; Huo, J.; Liao, W.B. Hydrogen gas alleviates postharvest senescence of cut rose 'Movie star' by antagonizing ethylene. Plant Mol. Biol. 2020, 102, 271-285. [CrossRef] [PubMed]

15. Fang, H.; Wang, C.L.; Wang, S.Y.; Liao, W.B. Hydrogen gas increases the vase life of cut rose 'Movie star' by regulating bacterial community in the stem ends. Postharvest Biol. Technol. 2021, 181, 111685. [CrossRef]

16. Bewley, J.D.; Bradford, K.J.; Hilhorst, H.; Nonogaki, H. Seeds: Physiology of Development, Germination and Dormancy, 3rd ed.; Seed ence Research; Springer: Berlin/Heidelberg, Germany, 2013.

17. Yang, L.; Liu, S.; Lin, R. The role of light in regulating seed dormancy and germination. J. Integer. Plant Biol. 2020, 62, 1310-1326. [CrossRef]

18. Penfield, S.; MacGregor, D.R. Effects of environmental variation during seed production on seed dormancy and germination. J. Exp. Bot. 2017, 68, 819-825. [CrossRef]

19. Munnê-Bosch, S.; Alegre, L. Cross-stress tolerance and stress 'memory' in plants: An integrated view. Environ. Exp. Bot. 2013, 94, 1-88. [CrossRef]

20. Baskin, C.C.; Baskin, J.M. Seeds: Ecology, biogeography, and evolution of dormancy and germination. Crop. Sci. 2000, 40, 334.

21. Lin, P.C.; Hwang, S.G.; Endo, A.; Okamoto, M.; Koshiba, T.; Cheng, W.H. Ectopicexpression of ABSCISIC ACID 2/GLUCOSE INSENSITIVE 1 in Arabidopsis promotes seed dormancy and stress tolerance. Plant Physiol. 2007, 143, 745-758. [CrossRef] 
22. Li, W.; Tran, L.S. Effects of ethylene on seed germination of halophyte plants under salt stress. Methods Mol. Biol. 2017, 1573, 253-259. [PubMed]

23. Li, J.P.; Yan, E.; Yang, X.G.; Bai, J.; Long, K.Z.; Li, H.; Xu, N. Effects of exogenous $\mathrm{H}_{2} \mathrm{~S}$ on the germination of tomato seeds under nitrate stress. J. Hortic. Sci. Biotechnol. 2015, 90, 39-46. [CrossRef]

24. Wang, P.; Zhu, J.K.; Lang, Z. Nitric oxide suppresses the inhibitory effect of abscisic acid on seed germination by S-nitrosylation of SnRK2 proteins. Plant Signal. Behav. 2015, 10, e1031939. [CrossRef]

25. Feil, R.; Lunn, J.E. Quantification of soluble sugars and sugar alcohols by LC-MS/MS. Methods Mol. Biol. 2018, 87-100.

26. Kaur, S.; Gupta, A.K.; Kaur, N. Gibberellic acid and kinetin partially reverse the effect of water stress on germination and seedling growth in chickpea. Plant Growth Regul. 1998, 25, 29-33. [CrossRef]

27. Liu, S.J.; Xu, H.H.; Wang, W.Q.; Li, N.; Wang, W.P.; Lu, Z.; Møller, I.M.; Song, S.Q. Identification of embryo proteins associated with seed germination and seedling establishment in germinating rice seeds. J. Plant Physiol. 2016, 196, 79-92. [CrossRef]

28. Xu, S.; Zhu, S.S.; Jiang, Y.L.; Wang, N.; Wang, R.; Shen, W.B.; Yang, J. Hydrogen-rich water alleviates salt stress in rice during seed germination. Plant Soil 2013, 370, 47-57. [CrossRef]

29. Zhang, C.P.; Li, Y.C.; Yuan, F.G.; Hu, S.J.; Liu, H.Y.; He, P. Role of 5-aminolevulinic acid in the salinity stress response of the seeds and seedlings of the medicinal plant Cassia obtusifolia L. Bot. Stud. 2013, 54, 18. [CrossRef] [PubMed]

30. Kaur, S.; Gupta, A.K.; Kaur, N. Effect of GA3, kinetin and in dole acetic acid on carbohydrate metabolism in chickpea seedlings germinating under water stress. Plant Growth Regul. 2000, 30, 61-70. [CrossRef]

31. Bu, R.F.; Xiao, X.M.; Liao, W.B.; Hu, Y.F.; Li, J.; Lv, J.; Wang, R.D.; Xie, J.M. Exogenous Si Alleviation of Autotoxicity in Cucumber (Cucumis sativus L.) Seed Germination is Correlated with Changes in Carbohydrate Metabolism. J. Plant Growth Regul. 2018, 37, 784-793. [CrossRef]

32. Su, J.C.; Preiss, J. Purification and proper ties of sucrose synthase from maize kernels. Plant Physiol. 1978, 61, 389-393. [CrossRef]

33. Shannon, J.C. Carbon-14 distribution in carbohydrates of immature zea mays kernels following co (2) treatment of intact plants. Plant Physiol. 1968, 43, 1215-1220. [CrossRef]

34. Zhang, Z.P.; Liu, Y.C.; Dai, H.B.; Miao, M.M. Characteristics and expression patterns of six $\alpha$-galactosidases in cucumber (Cucumis sativus L.). PLOS ONE 2021, 16, e0244714.

35. Sacher, J.A.; Hatch, M.D.; Glasziou, K.T. Sugar accumulation cycle in sugar cane. iii. physical \& metabolic aspects of cycle in immature storage tissues. Plant Physiol. 1963, 38, 348-354.

36. Pharr, D.M.; Sox, H.N.; Smart, E.L.; Lower, R.L.; Fleming, H.P. Identification and distribution of soluble saccharides in pickling cucumber plants and their fate in fermentation. J. Am. Soc. Hortic. Sci. 1977, 102, 406409.

37. Penfield, S.; Li, Y.; Gilday, A.D.; Graham, I.A. Arabidopsis ABA INSENSITIVE4 regulates lipid mobilization in the embryo and reveals repression of seed germination by the endosperm. Plant Cell. 2006, 18, 1887-1899. [CrossRef]

38. Bailly, C.; El-Maarouf Bouteau, H.; Corbineau, F. From intracellular signaling networks to cell death: The dual role of reactive oxygen species in seed physiology. C. R. Biol. 2008, 331, 806-814. [CrossRef]

39. Zhang, Y.; Chen, B.; Xu, Z.; Shi, Z.; Chen, S.; Huang, X.; Chen, S.; Wang, X. Involvement of reactive oxygen species in endosperm cap weakening and embryo elongation growth during lettuce seed germination. J. Exp. Bot. 2014, 65, 3189-3200. [CrossRef]

40. Kittock, D.L.; Law, A.G. Relationship of seedling vitality to respiration and tetrazolium chloride reduction by germinating wheat seeds. Agron. J. 1968, 60, 286-288. [CrossRef]

41. Vasquez-Tello, A.Y.; Zuily-Fodil, Y.; Thi, A.P.; Da Silva, J.V. Electrolyte and Pi leakages and soluble sugar content as physiological tests for screening resistance to water stress in Phaseolus and Vigna species. J. Exp. Bot. 1990, 41, 827-832. [CrossRef]

42. Bradford, M.M. A rapid and sensitive method for the quantitation of microgram quantities of protein utilizing the principle of protein-dye binding. Anal. Biochem. 1976, 72, 248-254. [CrossRef]

43. Li, C.X.; Bian, B.T.; Gong, T.Y.; Liao, W.B. Comparative proteomic analysis of key proteins during abscisic acid-hydrogen peroxide-induced adventitious rooting in cucumber (Cucumis sativus L.) under drought stress. J. Plant Physiol. 2018, 229, 185-194. [CrossRef]

44. Dan, Y.Y.; Niu, Y.; Wang, C.L.; Yan, M.; Liao, W.B. Genome-wide identification and expression analysis of the trehalose-6phosphate synthase (TPS) gene family in cucumber (Cucumis sativus L.). Peer J. 2021, 9, e11398. [CrossRef]

45. Rajjou, L.; Rajjou, L.; Gallardo, K.; Debeaujon, I.; Vandekerckhove, J.; Job, C.; Job, D. The effect of alpha-amanitin on the Arabidopsis seed proteome highlights the distinct roles of stored and neosyn the sized mRNAs during germination. Plant Physiol. 2004, 134, 1598-1613. [CrossRef]

46. Jacobsen, J.V.; Hanson, A.D.; Chandler, P.C. Water stress enhances expression of an $\alpha$-amylase gene in barley leaves. Plant Physiol. 1986, 80, 350-359. [CrossRef]

47. Todaka, D.; Matsushima, H.; Morohashi, Y. Water stress enhances $\beta$-amylase activity in cucumber cotyledons. J. Exp. Bot. 2000, 51, 739-745. [CrossRef]

48. Xu, X.; Liao, G.; Huang, C.; Zhong, M.; Jia, D.; Qu, X.; Liu, Q.; He, Y.; Li, Y. Differences of sucrose accumulation concentration and related genes expression between two sucrose accumulation types of Actinidia eriantha. Sci. Rep. 2020, 10, 20474. [CrossRef] 